\title{
1 Examining high-resolution survey methods for monitoring cliff erosion 2 at an operational scale
}

3 Pauline Letortu ${ }^{\mathrm{a}}$, Marion Jaud ${ }^{\mathrm{b}}$, Philippe Grandjean ${ }^{\mathrm{c}}$, Jérôme Ammann ${ }^{\mathrm{b}}$,

4 Stéphane Costa ${ }^{\mathrm{d}}$, Olivier Maquaire ${ }^{\mathrm{d}}$, Robert Davidson ${ }^{\mathrm{d}}$, Nicolas Le

5 Dantec $^{\mathrm{b}, \mathrm{e}}$, Christophe Delacourt ${ }^{\mathrm{b}}$

6 a'University of Bretagne Occidentale, CNRS, UMR LETG, IUEM, Rue Dumont d'Urville,

$7 \quad$ Plouzané, 29280, France; tel: +33 290915588; pauline.letortu@univ-brest.fr

$8{ }^{\mathrm{b}}$ University of Bretagne Occidentale, CNRS, UMR Géosciences Océan, IUEM, rue

9 Dumont d'Urville, Plouzané, 29280, France; tel: +33 298498710

10 'University of Lyon 1, CNRS, UMR Sciences de la Terre, 2 rue Raphaël Dubois,

11 Bâtiment GEODE, Villeurbanne, 69622, France; tel: +33 472728499

12 dNormandie Univ, UNICAEN, CNRS, UMR LETG, Esplanade de la Paix, Caen, 14000,

$13 \quad$ France; tel +33231565141

$14{ }^{\mathrm{e}}$ CEREMA - Cerema, Direction Eau Mer et Fleuves, 134 Rue de Beauvais, Margny-lès-

15 Compiègne, 60280, France

16 


\section{Examining high resolution survey methods for monitoring cliff erosion 18 at an operational scale}

This paper aims to compare models from terrestrial laser scanning (TLS), terrestrial photogrammetry (TP), and unmanned aerial vehicle photogrammetry (UAVP) surveys to evaluate their potential in cliff erosion monitoring. TLS has commonly been used to monitor cliff-face erosion (monitoring since 2010 in Normandy) because it guarantees results of high precision. Due to some uncertainties and limitations of TLS, TP and UAVP can be seen as alternative methods. First, the texture quality of the photogrammetry models is better than that of TLS which could be useful for analysis and interpretation. Second, a comparison between the TLS model and UAV or TP models shows that the mean error value is mainly from 0.013 to $0.03 \mathrm{~m}$, which meets the precision requirements for monitoring cliff erosion by rock falls and debris falls. However, TP is more sensitive to roughness than UAVP, which increases the data standard deviation. Thus, UAVP appears to be more reliable in our study and provides a larger spatial coverage, enabling a larger cliff-face section to be monitored with a regular resolution. Nevertheless, the method remains dependent on the weather conditions and the number of operators is not reduced. Third, even though UAVP has more advantages than TP, the methods could be interchangeable when no pilot is available, when weather conditions are bad or when high reactivity is needed.

Keywords: Coastal cliff erosion; monitoring; terrestrial laser scanning; terrestrial photogrammetry; UAV photogrammetry; Normandy

\section{Introduction}

Changes to coastal cliffs are complex because of the sudden and stochastic natures of erosion in time and place and the diversity of movements (rock falls and debris falls according to the typology of Varnes). Despite contributions to research into geomorphological processes on rocky coasts in recent years, the respective contribution of the triggering factors responsible for erosion is still difficult to determine (Naylor et al. 2010; Lim et al. 2011; Letortu et al. 2015a; Laute et al. 2017). 
As quantifying changes in unstable and subvertical cliff face is difficult and sometimes dangerous, in situ data are mainly collected by remote-sensing methods.

Data with a horizontal or quasi-horizontal point of view (side scanning a vertical

structure as the cliff face) allow all changes to be observed because the data capture cliff face changes which reflect failures and deposits anywhere on the cliff profile (contrary to cliff top and cliff base). High spatial resolution and high temporal repetitiveness are essential to reveal patterns of cliff failure (location, time) and therefore to better understand and forecast the processes responsible for cliff erosion (e.g. Collins and Sitar 2008; Hampton 2002; Vann Jones et al. 2015; Young 2015).

Different methods terrestrial Laser Scanning (TLS), Aerial Laser Scanning

(ALS), Mobile Laser Scanning, Unmanned Aerial Vehicle Photogrammetry (UAVP), Terrestrial Photogrammetry (TP) are available for cliff monitoring depending on the precision, the spatial and temporal scales, and costs (e.g., Young et al. 2010; James and Robson 2012; Michoud et al. 2014). As reported in James and Robson (2012), for restricted areas (ranges of 10-500s of meters) terrestrial laser scanners or TP can be used. Over larger areas, aerial photogrammetry, aerial laser scanners, and space-based radar and photogrammetric techniques are possible. (French National Service Observation for the study of coastal and coastline dynamics),

66 we survey the cliff-face evolution in Petit Ailly site in Varengeville-sur-Mer

67 (Normandy, France) to quantify fine-scale changes, to visualize the modalities of 68 evolution and to contribute to the debate about the agents responsible for the retreat of 69 the chalk cliffs. Since October 2010, a 3D monitoring of the cliff face has been performed by terrestrial laser scanner (an active remote-sensing instrument) at very high

71 spatial resolution and with pluricentimeter precision $( \pm 0.03 \mathrm{~m})$ every $3-4$ months 
72 (Letortu et al. 2015b). It enables reliable, homogeneous, frequent and perennial

73 monitoring of rock falls and debris falls. However, the TLS routine is expensive and

74 cumbersome and therefore requires several operators. UAVP and TP surveys may be

75 efficient alternatives offering data of equivalent quality.

76 Is the accuracy of close-range techniques, such as TP and UAVP, sufficient in

77 comparison with the more expensive and cumbersome TLS routine for monitoring cliff-

78 face erosion? The answer to this question involves many topics: (1) the resolution

79 and/or ground sampling distance (2) the spatial coverage (3) the accuracy and precision

80 of the datasets for diachronic surveys of individual and mass movements, and (4) an

81 easy-to-use acquisition protocol for the site configuration and data processing. If the

82 different techniques achieve the same level of data quality, these methods could be

83 interchangeable, depending on weather conditions and people availability, without any

84 impact on the monitoring results.

85 Thus, this article presents an original comparison for such environment of three

86 high-resolution remote-sensing methods implemented for 28 January 2016: (1)

87 measurement by TLS and two photogrammetric methods based on Structure from

88 Motion/Multi-View Stereophotogrammetry (SfM-MVS) techniques from (2) UAV

89 photographs and (3) terrestrial photographs. After a brief description of the study area,

90 this paper details the survey methodology. Finally, the results of the cliff-face

91 monitoring are presented and discussed.

\section{$92 \quad 2$ Study area}

93 The study takes place near Dieppe, in Seine-Maritime (Normandy) in the northwestern

94 part of France and along the Channel. Geologically, the Upper Normandy coastal cliffs

95 (60-70 m high on average ) extending from Cap d'Antifer to Le Tréport (100 km) are 
made of various chalk with flints of Upper Cretaceous (Pomerol et al. 1987; Mortimore and Duperret 2004). The different stages of chalk (from the oldest to the newest: Cenomanian, Turonian, Coniacian, Santonian and Campanian) present slight variations in facies and fine sedimentary discontinuities, inducing some subtle resistance contrasts.

100 Over these chalk strata, the usual residual flint formation (Laignel 1997; Costa et al.

101 2006) have been replaced by a bed of clay and sand sediments about 10-30 m thick of

102 Paleogene age (Bignot 1962), especially in Sainte-Marguerite-sur-Mer, Varengevillesur-Mer, and Sotteville-sur-Mer (Figure 1). The Seine-Maritime cliff coast is characterized by the regressive dynamics, coming out as instantaneous falls affecting all or part of the cliff. A monitoring of the regressive dynamics of the cliff top between

1061966 and 2008 shows a retreat rate of $0.15 \mathrm{~m} /$ year with high spatial variability in Upper

107 Normandy (Letortu et al. 2014).

108 The SNO DYNALIT site of Petit Ailly is located along Cap d'Ailly

109 (https://www.dynalit.fr/fr/falaises/ailly-puys). More precisely, it lies on either side of

110 the Petit Ailly dry valley in Varengeville-sur-Mer (Figure 2). This site is made up of

111 Santonian chalk, covered by a bed of clay and sand of Paleogene age, prone to erosion.

112 It has a high erosion rates calculated from TLS surveys: from October 2010 to June

113 2017, the erosion rate is $0.38 \mathrm{~m} /$ year with a fallen volume of $12965 \mathrm{~m}^{3}\left( \pm 155 \mathrm{~m}^{3}\right)$ due to

114 rock falls and debris falls. Nevertheless, these average retreat rates are not

115 representative of the erosion which occurs suddenly caused by rockfalls. For example,

116 in February 2014, a rock fall of approximately $5000 \mathrm{~m}^{3}$ resulted in a cliff-top retreat of

$11711 \mathrm{~m}$ in a few seconds.

118 The studied cliff face is characterized by (1) its verticality (from $70^{\circ}$ to

119 overhang); (2) its height (about 30-40 m); (3) its spatial extent (250 m long); (4) debris

120 falls, which are individual movements of blocks or flakes (up to decimeters), and rock 
121 falls, which describe large-scale mass movements from all or part of the cliff face; and

122 (5) its limited accessibility (rock falls, tide constraints, difficulty in setting up targets at 123 the cliff top).

\section{$124 \quad 3$ Methods}

\section{$125 \quad 3.1$ Data collection}

\section{3.1.1 Terrestrial laser scanner data collection and ground control points}

127 A terrestrial laser scanner is an optical active remote-sensing technology that can

128 measure the position (distance and angle) of a point relative to the device using the time

129 of flight of laser pulses reflected by the point to be measured.

130 The instrument used in this study is a Riegl® VZ-400 (Figure 2(6)) emitting a

131 laser pulse in the near-infrared $(1550 \mathrm{~nm})$, which records unique echo digitization but

132 allows the digitized echo-signals (waveform data) to be processed in Riegl® software.

133 This instrument provides scan data acquisition with theoretical $0.005 \mathrm{~m}$ accuracy and

$1340.003 \mathrm{~m}$ precision at a range of $100 \mathrm{~m}$. The measurement range can reach up to $600 \mathrm{~m}$

135 while the measurement rate can reach up to 122,000 measurements per second with a

136 wide field of view of $100^{\circ}$ vertical (from $30^{\circ}$ to $130^{\circ}$ ) and $360^{\circ}$ horizontal (Riegl 2014).

137 Moreover, the Riegl® VZ-400 is equipped with a Nikon D800 camera, which provides

138 photographs. These pictures can be used to drape a 2D image on the 3D point cloud but

139 are not an absolute requirement for topographic measurement. In Varengeville-sur-Mer,

140 the two scanner stations are positioned on the beach at about $75 \mathrm{~m}$ from the cliff face.

141 TLS acquisition involves a $360^{\circ}$ horizontal and $100^{\circ}$ vertical scan with an angular

142 resolution of $0.04^{\circ}$ in both directions, providing a dense 3D point cloud (more than 22.5

143 million points) and five photographs in $9 \min (20 \%$ overlap by default). These 
144 instruments are heavy, $20 \mathrm{~kg}$ for the scanner and $1 \mathrm{~kg}$ for the Nikon camera, and require

145 complementary equipment (a tripod, cases, batteries, targets and a total station).

146 To carry out georeferencing and obtain repeated surveys of high accuracy, the

147 data acquisition process requires additional equipment: reflective targets $(10 \mathrm{~cm}$ high

148 cylinders, $0.15 \mathrm{~kg}$, Figure 2(4)) used as ground control points (GCPs) and a total station

149 to measure them (Figure 2(2)). Contrary to the GPS, the total station measures points

150 close to the cliff front without a mask effect. The Trimble M3 total station is precisely

151 positioned at a single location previously known by raw data GPS post-processing.

152 Knowing the reflective targets absolute coordinates enables the point cloud acquired in

153 a relative coordinate system to be projected in an absolute coordinate system (Lambert

15493 and associated RGF93 and IGN69, official reference system in France; EPSG:

155 2154). For the TLS survey at Petit Ailly, laser scans were performed from two stations

156 with 15 targets as GCPs (Figure 3). To reduce the alignment error of the point cloud,

157 targets are numerous and with different distances from the scanner (as long as they all

158 remain visible).

\subsubsection{Terrestrial photo collection}

160 Terrestrial photographs are acquired with a Nikon D800 reflex camera $(1 \mathrm{~kg})$ with a

161 focal length of $35 \mathrm{~mm}$, taking 36 Mpix photos. To collect data on the cliff front, as

162 recommended by James and Robson (2012), images of the area of interest are acquired

163 from different positions. As depicted in Figure 5a, the camera orientations are not

164 parallel but rather converge on the scene. The procedure to collect digital photographs is

165 quite easy to implement. It involves short distances between the acquisition positions

166 (around 2-3 m when taking photos at $\sim 20 \mathrm{~m}$ from the cliff foot) and photos taken at

167 angular intervals of $10-20^{\circ}$, over a wide range of angles. To obtain a high-quality 
168 dataset, photographs should overlap by at least $60 \%$ (ideally, a point should be seen at

169 least three times) and must capture the area with at least two shooting angles. In 23 min,

170 the whole cliff section ( $250 \mathrm{~m}$ long) was covered by a dataset of 153 photographs

171 collected along the baseline depicted in Figure 3. The overlap enables that any point in

172 the studied cliff face being present in six to more than nine photographs.

\subsubsection{UAV photo collection}

174 The drone survey is implemented using an electric hexacopter UAV, called DRELIO 10

175 (multi-rotor DS6 platform assembled by DroneSys). A collapsible frame enables it to be

176 folded for easy transportation. With a $0.8 \mathrm{~m}$ diameter, the DRELIO 10 weighs less than

$1774 \mathrm{~kg}$ and can handle a payload of $1.6 \mathrm{~kg}$. The flying time is about $20 \mathrm{~min}$. On a tilting

178 gyro-stabilized platform, a Nikon D800 reflex camera with a focal length of $35 \mathrm{~mm}$ is

179 set up. The camera takes 36 Mpix photographs in intervalometer mode every $2 \mathrm{~s}$. The

$180 \mathrm{DJI}^{\circledR}$ software iOSD runs the flight control. For delicate steps of the take-off and

181 landing, the pilot prefers to control the UAV thanks to ground station software.

182 The dataset is collected along the yellow baseline depicted in Figure 3. As

183 shown in Figure 5b, data at the cliff top were collected by the camera that is in the nadir

184 position. To collect data on the cliff front, the camera was forward-pointed and tilted at

$18525^{\circ}$. In this case, the flight has to be performed in manual mode to keep the camera

186 turned toward the cliff face. The flight lasted around $8 \mathrm{~min}$. In this configuration, the

187 dataset is composed of 110 oblique and nadir images (that will be processed together),

188 any point in the studied cliff face being present at least in 9 photographs.

190 Like the TLS survey, TP and UAVP need GCPs (targets) to record the models in a

191 reference coordinate system and to achieve models of the highest quality, in terms of 
192 both geometrical precision and georeferencing accuracy. The absolute coordinates are

193 provided by additional equipment : the total station (previously described). In order to

194 obtain a high-quality final model (James and Robson 2012) and help to mitigate doming

195 effects caused by an incorrect camera model and radial distortion (James and Robson

196 2014), a large number of GCPs is recommended. The GCPs need to be distributed

197 throughout the area of interest (Javernick et al. 2014; Smith et al. 2014) without linear

198 configurations. They should ideally cover both the margins and the center of the area of

199 interest, with a good range of values in each spatial dimension. However, in a cliff

200 context, access to the cliff face is dangerous due to frequent rock falls. It can therefore

201 be difficult to ensure targets are clearly visible while guaranteeing the safety of the

202 person installing them at the top of the cliff. The lack of targets on the upper part of the

203 cliff face may create distortion. To avoid this concern, the photograph acquisition

204 protocol was implemented cautiously. The UAV camera was forward-pointed and tilted

205 at $25^{\circ}$ with photographs at different distances from the cliff face to reduce distortion.

206 For TP, a great variety of viewing angles of terrestrial photographs was taken to limit

207 the doming effect (Jaud et al. 2017b). A total of 17 targets were used for TP with

208 different configurations: 9 were vertically positioned on the area of interest (center of

209 orange crosses, $40 \mathrm{~cm}$ high, painted on the lower part of the cliff face, Figure 2(5))

210 while 8 targets (circular disks, $23 \mathrm{~cm}$ in diameter, Figure 2.1) were horizontally

211 positioned on the beach (Figure 3). For UAVP, 22 targets (circular disks, $23 \mathrm{~cm}$ in

212 diameter, Figure 2(1)) were horizontally positioned on the beach, on the lower part of

213 the valley slope and on the cliff top (Figure 3). 


\subsection{Data processing}

\section{3.2.1 Terrestrial laser data processing and absolute error quantification}

216 The main steps in the TLS data processing are (1) georeferencing and point cloud

217 assembly (RiscanPRO® software); (2) manual point cloud filtering including areas

218 without overlap with previous TLS data, noise and vegetation (Fledermaus $®$ ); and (3)

219 Delaunay 2.5D meshing (best fit plane, Cloudcompare ${ }^{\circledR}$ ).

220 The scanning survey of each position is recorded as a 3D point cloud $(\mathrm{x}, \mathrm{y}, \mathrm{z})$ in a

221 reference system relative to each position of the scanner in the field. The accuracy of

222 georeferencing is carried out by comparing the position of the control points in the

223 model with the GCPs precisely measured on the field using the Root Mean Square Error

224 method (measuring the differences between values predicted by a model and the values

225 really observed) (Kaiser et al. 2014; Eltner et al. 2016). This accuracy assessment is

226 only valid if the point cloud is considered consistent (distortion due to atmospheric

227 effects is neglected). For the first and second stations, the standard deviations of fit

228 residues are 0.0091 and $0.0093 \mathrm{~m}$, respectively. The absolute error on the data

229 (accuracy) is the sum of the TLS instrumental errors, the total station measurement

230 errors, and topographic inaccuracies during georeferencing. The theoretical instrument

231 accuracy of the TLS is very high $( \pm 0.005 \mathrm{~m}$ at a range of $100 \mathrm{~m})$, so the main source of

232 error comes from the total station survey, which measures the target positions with

233 accuracy from 0.01 to $0.03 \mathrm{~m}$.

234 In a context of recurrent TLS surveys, a procedure of accuracy assessment has

235 been implemented. It is based on the comparison of the position of 3 fixed points

236 (surveyor nails located on the descending road to the sea) measured by the total station

237 during the 18 successive missions carried out within the framework of the DYNALIT

238 observatory. The 6 July 2011 topographical survey is defined as a reference because the 
survey conditions were optimal. Identified thanks to their dispersion from the reference

240 data, the poor measurements are removed. The validated data have a maximum

241 dispersion ellipse of $0.018 \mathrm{~m}$ in $\mathrm{x}, 0.019 \mathrm{~m}$ in $\mathrm{y}$ and $0.033 \mathrm{~m}$ in $\mathrm{z}$ (Figure 4).

242 For diachronic comparisons to quantify local erosion rates, the point clouds are

243 adjusted relative to this point cloud of reference (6 July 2011) using a best fit algorithm.

244 To keep the consistency of this protocol, the comparison between TLS data and

245 photogrammetric data is also based on a best fit adjustment.

\subsubsection{Photograph data processing and precision}

247 The procedure for deriving 3D point clouds from photographs is based on the SfMMVS workflow. The SfM-MVS algorithm is implemented by AgiSoft $®$ PhotoScan Professional (version 1.2) (Figure 5). The positions of the GCPs are imported into Agisoft@ PhotoScan and, concurrently, the GCPs are pointed out on the photographs to compute the georeferenced 3D point cloud.

The 3D surface reconstruction is divided into two main steps:

- Camera alignment by bundle adjustment. Tie points are detected and matched on overlapping photographs so as to compute the external camera parameters (position and orientation) for each picture. From 17 to 22 GCPs (targets located on the cliff front and on the beach for TP; targets on the beach for UAVP) are tagged to georeference data and refine the internal parameters of the camera.

- From the estimated camera positions and the pictures themselves, each tie point, so as to build a dense point cloud. 

surveyor nails (fixed in a horizontal position) are not always visible in these datasets.

263 TLS data are considered the reference dataset for comparison in this paper, so, as

264 previously mentioned, TP and UAVP point clouds have been fitted to TLS data.

265 Therefore, the measure of precision of the photogrammetric reconstruction for TP and

266 UAVP datasets is assessed relative to the synchronous TLS dataset. The best fit RMS

267 error is of $0.04 \mathrm{~m}$ between TP and TLS and UAVP and TLS.

\subsection{Data comparison}

269 First of all, TLS and photogrammetric methods (UAVP and TP) differ in the nature of 270 collected data and so resulting products. The main advantage of UAVP and TP is that 271 they provide textured models of better quality than the TLS model. When scanning a

272 site, by default, the TLS takes only five photographs for a $360^{\circ}$ horizontal angle (with 273 an overlap of 20\%). This is not enough to create, from all angles, a textured model 274 taking into account the terrain (Figure 6b). It is possible to increase the overlap but 275 because of fixed points of view of TLS stations, it would be hard to match the 276 photogrammetric model. In fact, the process of SfM-MVS itself involves the use of 277 ten(s) of high-resolution photographs, thus enabling the algorithm to choose perfectly 278 the relevant photographs to texture each parcel of the model (Medjkane et al. accepted).

279 It thus constitutes an important asset for the morphological analysis and interpretation 280 of landscapes (Figure $6 \mathrm{c}$ and d).

A first comparison of raw data is provided in Table 1. For the TP dataset,

282 because the photographs were taken closer to the cliff face than for the other datasets, 283 more photographs were needed to cover the area of interest so the sampling distance on

284 the cliff face was greater than for UAVP (Table 1). The volume of data was so large 
285 that it was not manageable; it had to be processed in chunks. The steps for a more

286 advanced quantitative comparison were

287

288

289

(1) Cleaning the point cloud around the cliff face to obtain a good surface overlap;

(2) Subsampling TP and UAVP datasets to obtain manageable ones. The distance sampling was a point every $0.06 \mathrm{~m}$ to have the same mean sampling as the TLS point cloud, considered the reference;

(3) Fitting TP or UAVP models to the TLS point cloud used as the reference with Cloudcompare and 3DReshaper software; and

(4) Comparison of the subsampled fitted point clouds (TP_SF, UAVP_SF) with the TLS mesh (2.5D Delaunay mesh).

After dataset subsampling $(0.06 \mathrm{~m})$ of TP and UAVP models, quick filtering around the cliff face and the beach and a fitting between TP or UAVP models and the reference data (i.e. the TLS point cloud), the final point clouds can be quantitatively compared (Table 2).

As in many papers (Westoby et al. 2012; Kaiser et al. 2014; Eltner et al. 2015; Smith et al. 2016), we consider TLS models as the reference although they may also have bias. As declared by Kromer et al. (2015), "the ability to detect change by comparing a series of point clouds is controlled by the point cloud accuracy, precision, survey design and terrain factors." For the TLS point cloud, these parameters are, as Kromer et al. (2015) point out:

the scanner target distance (Teza et al. 2007), vegetation (Su and Bork 2006), incidence angle (Sturzenegger and Stead 2009; Lato et al. 2010; Pesci et al. 2011), surface reflectance (Csanyi and Toth 2007), surface roughness (Lague et al. 2013), atmospheric conditions (Beckmann 1965), heterogeneity in point spacing (Raber et al. 2007), alignment error (Oppikofer et al. 2009) and instrument specifications (Pirotti 2013). Some of these factors contribute to the random Gaussian point-to- 
314 because (1) within the TLS dataset, measurement errors related to the accuracy of the

315 laser are constant $(0.005 \mathrm{~m}$ at a range of $100 \mathrm{~m})$ while errors inherent in georeferencing

316 are transmitted to the whole cloud; (2) vegetation is scarce on the cliff face; (3) the

317 incidence angle is close to the normal direction and so the noise and systematic error of 318 the TLS point cloud are likely to be low.

319 For a quantitative data comparison, four calculation algorithms can be used

320 (Kromer et al. 2015): (1) M3C2 (2) mesh to point or mesh to mesh change detection (3)

321 spatial filtering (with calibration) and (4) space-time filter (with calibration). We used mesh (for the TLS dataset) to point (photogrammetry datasets) because (1) the spatial distribution of density from TLS, TP, and UAVP is different leading to an overassessment of the distance between points; (2) the shortest distance calculation enables change in different directions to be interpreted; and (3) noise is reduced through the creation of the mesh of TLS data.

\section{$327 \quad 4$ Results and discussion}

\subsection{Global quality assessment}

329 The characteristics of the resulting point clouds differ from one method to another

330 (Table 2). As shown in Figure 7: cloud due to the positions of the TLS stations. The most homogeneous densities are unsurprisingly UAVP and TP not only because of subsampling but also 
because of the modus operandi, with a moving point of view during data collection. UAVP has the most homogeneous density due to the automatic snapping every $2 \mathrm{~s}$.

- The best spatial coverage is observed for the UAVP model with no occlusion.

UAVP_SF datasets with the TLS dataset highlight the low error value (millimeter to centimeter values), which is relevant to observe debris falls. The mean error value is mainly from $0.013 \mathrm{~m}$ to $0.03 \mathrm{~m}$ (Figure $8 \mathrm{c}$ and d). However, artifacts on datasets have values superior to $1 \mathrm{~m}$. These artifacts could be partially due to the error-assessment method overestimating the error when the point cloud density is drastically different between the compared datasets (because of occlusion). Over the whole datasets, the mean error value is of $0.005 \mathrm{~m}$ for the TP model, whereas it is of $0.014 \mathrm{~m}$ for the UAVP one. Thus, the TP model is more precise than the

347 UAVP one relative to the TLS reference. Nevertheless, the standard deviation is lower for the UAVP_SF model than for the TP_SF one, so the dispersion of the measurement error is lower (Table 3). In our comparison, the most important issue is to have a low measurement error dispersion in order to obtain a reliable dataset (Figure 8a and b), and so, for this purpose, the UAVP dataset appears to be the most relevant. terrain factors (rock falls, overhanging areas, hollow areas, vegetation, and caves).

354 Occlusion is minimized with the TP and UAVP surveys relative to the TLS surveys 355 because the SfM-MVS survey covered the whole cliff face thanks to a greater number of points of view. The UAV flight provides the largest number of cliff-face views and can avoid the concern about overhanging. With the TLS surveys, time limitations determine the number of possible tripod set-ups meaning that gaps may occur in the 
359 final point cloud owing to occlusion. In such a context, a small number of targets are an

360 important issue because decreasing the duration per station will improve the spatial

361 coverage and the accuracy of the TLS surveys (Jaud et al. 2017a).

362

363

364

365

366

367

368

369

370

371

372

373

374

375

376

377

378

379

380

381

\subsection{Local quality assessment}

In the previous data comparison, when a point in one dataset is situated in a zone without data (due to occlusion) in the compared dataset, the point to mesh distance is measured relative to the nearest point, introducing an overestimation of the error. To avoid this, we defined strips of the cliff face (Figure 9) considered to be without artifacts in the error assessment (without vegetation, rock falls, complex morphology, occlusion, etc.).

First, for all cliff-face strips, both data comparisons give nearly the same mean error (0.015 m for TP-TLS comparison and $0.016 \mathrm{~m}$ for UAVP-TLS comparison) and standard deviation values $(0.031$ and $0.026 \mathrm{~m}$, respectively, for TP-TLS and UAVP-

TLS comparisons). So, without occlusion, the results from both methods seem to be comparable.

Second, the mean error values are similar between the whole cliff face and strips for UAVP (0.014 and $0.015 \mathrm{~m}$, respectively). The standard deviation is slightly lower for the strips than for the whole cliff face $(0.026$ against $0.037 \mathrm{~m})$ due to surface homogeneity, which limits overestimation. For TP, the results are different. The mean error value is higher for the strips than for the whole cliff face $(0.016$ and $0.005 \mathrm{~m}$, respectively), whereas the standard deviation is lower for the strips than for the whole cliff face ( 0.031 and $0.05 \mathrm{~m}$, respectively). This means that occlusion significantly affects the TP results. UAVP appears to be a more reliable and stable method whichever 
382 surface is studied (cliff-face morphology, vegetation, etc.) whereas TP is much more

383 sensitive to roughness.

\subsection{Elements for choosing a relevant survey method}

385 According to our results, the choice of a suitable method for cliff erosion monitoring depends on many criteria that are summarized in Table 4.

The main advantages of TLS are the precision of the data and the low dispersion due to the consistency of the dataset (including the georeferencing step). Another advantage is the long battery life, which enables many surveys to be carried out, especially if the distance between stations can be increased to cover a larger area and a single target can be used per survey (visible from every TLS station). The main disadvantages of TLS remain the very expensive purchase and maintenance costs and the weight. TLS field campaigns have low ability to implement survey because the

394 stations have to be close to the area of interest and the instrument is heavy $(50 \mathrm{~kg}$

395 including instruments, cases, batteries, a tripod and targets) and cumbersome. Easy

396 access to the area is necessary. Moreover, the weather conditions are a restraining factor

397 (in addition to tide times) since the instrument is highly sensitive to rain, wind, and fog,

398 which may be frequent in coastal areas (Table 4). The alternative of a hand-held mobile

399 laser scanner, which has been recently used for cliff-erosion monitoring (James and

400 Quinton 2014), could overcome the portability concern but the purchase of new material 401 is not desirable.

The main strengths of TP are very long battery life, very low sensitivity to bad

403 weather, very good ability to implement survey, and low cost. Because this method

404 needs a light instrument, which has a low energy consumption, the survey can be done

405 with the highest battery life. Thanks to these major advantages, the survey can be highly 
reactive and easily carried out before/during/after a morphogenesis event. The main

407 weaknesses are the dispersion of the data and the processing duration (Table 4).

408 The main strengths of UAVP are the modus operandi, which can be adapted to

409 the configuration of the study area (very high flexibility in the ability to capture the

410 interest area) and very high speed of data acquisition. With a UAV pilot, sites that are

411 difficult to access can be monitored since the take-off and landing can be in the

412 hinterland. With a suitable flight plan, the distance-to-target can be varied to avoid

413 occlusion due to topographic complexities (Abellan et al. 2016). However, having a

414 pilot available (a key skill) can be a major constraint and weather conditions have to be

415 dry, with neither strong wind nor fog. Mild weather conditions may be a limiting factor

416 in coastal zones. Moreover, as TP, the duration of data processing may be longer than

417 for the TLS data (Table 4).

418 In the context of the observatories, the camera network (photo or video) could

419 be a complementary approach. More precisely, this instrumentation would not be used

420 for a precise quantification of observed changes but seems more suitable for a site of a

421 hundred meters maximum to capture erosion events because of its higher temporal

422 resolution. In fact, the time sampling of the TLS, PT, and UAVP surveys does not

423 provide this kind of information. The precise time of the observed change is important

424 to constrain the driving forces and, if possible, identify the triggering factor. Moreover,

425 with this information, a quantification survey can be planned when necessary. Thus,

426 video monitoring, combined with the precise quantification of changes thanks to TLS,

427 UAVP or TP, could improve the understanding of the agents and processes responsible

428 for cliff erosion and failure forecast. However, deployments of video cameras are not

429 possible everywhere because of the site configuration. A camera network needs to be 
430 installed on a fixed support (e.g., on large rocks that can protect cameras from waves,

431 spray and abrasion) with a suitable view angle (embayed coast).

432 Each of the techniques presented in this paper has different strengths and weaknesses.

433 The choice of the instrument(s) (it could be a combination) to carry out monitoring

434 depends on the required precision, the costs, the site configuration (accessibility, height, 435 danger, morphology, etc.), the time, the people and skills available, as well as the 436 weather conditions and legal framework (for UAV).

\section{Conclusion}

438 Because the precision of a centimeter range (mean error value from 0.013 to $0.03 \mathrm{~m}$ ) is 439 reached by the TP and UAVP, these can be seen as complementary methods to TLS 440 cliff erosion monitoring in Normandy. However, it should be remembered that TP is 441 sensitive to roughness, which can increase the standard deviation of data. Moreover, in 442 order to obtain textured models of good quality, SfM-MVS models are clearly better 443 than those of TLS. Because the TLS survey is cumbersome and expensive, the lower 444 costs of TP or UAVP seem attractive. However, it is important to bear in mind that the 445 choice is specific to accuracy expectations; the site configuration (accessibility, height, 446 danger, morphology, etc.); the time available to do the survey; the people and skills 447 available; financial resources; weather conditions and the legal framework (for UAV).

448 For our cliff erosion survey, TLS remains a good option because the methodological 449 framework can be improved (e.g. a single target) but UAVP is an interesting alternative: 450 (1) with a large spatial coverage in a few minutes with numerous viewpoints that avoid 451 occlusion; (2) a lighter weight and a higher flexibility in the ability to capture interest 452 areas than TLS; and (3) easy site access because the take-off and landing can occur in 453 the hinterland. However, this method needs a qualified pilot and if the area of interest is 
near sensitive stakes (houses, airports, etc.), it could take time to obtain the flight

authorization. Another main weakness is its high sensitivity to weather conditions

(especially wind and rainfall), which can delay many surveys in the coastal zone.

Therefore, if a reactive method is needed, TP could be a good option. Despite some drawbacks, SfM-MVS has changed topographic data collection in a wide range of environmental settings and should have a bright future because of technical

460 developments in the devices and software.

References

Abellan, A., Derron, M. H., and M. Jaboyedoff. 2016. "Use of 3D Point Clouds in Geohazards. Special Issue: Current Challenges and Future Trends.” Remote Sensing 8 (130). doi:10.3390/rs8020130.

Beckmann, P. 1965. "Signal degeneration in laser beams propagated through a turbulent atmosphere." Journal of Research of National Bureau Standards. Sect. D: Radio Science 69D: 629-640.

Eltner, A., Schneider, D., and H. G. Maas. 2016. "Image-based surface reconstruction in 483 geomorphometry - merits, limits and developments." Earth Surface Dynamics 4: 359-389. 
Hampton, M. 2002. "Gravitational failure of sea cliffs in weakly lithified sediment." Environmental and Engineering Geoscience 8 (3): 175-191.

James, M. R., and J. N. Quinton. 2014. "Ultra-rapid topographic surveying for complex environments: the hand-held mobile laser scanner (HMLS)." Earth Surface Processes and Landforms 39: 138-142.

James, M. R., and S. Robson. 2012. "Straightforward reconstruction of 3D surfaces and topography with a camera: accuracy and geoscience application." Journal of Geophysical Research: Earth Surface 117: F03017. doi: 10.1029/2011JF002289.

James, M. R., and S. Robson. 2014. "Mitigating systematic error in topographic models derived from UAV and ground-based image networks." Earth Surface Processes and Landforms 39: 1413-1420. doi: 10.1002/esp.3609.

Jaud, M., Letortu, P., Augereau, E., Le Dantec, N., Beauverger, M., Cuq, V., Prunier, C., Le Bivic, R., and C. Delacourt. 2017a. “Adequacy of pseudo-direct georeferencing of terrestrial laser scanning data for coastal landscape surveying against indirect georeferencing." European Journal of Remote Sensing 50 (1): 155-165.

Jaud, M., Passot, S., Allemand, P., Le Dantec, N., Grandjean, P., Ammann, J., and C. Delacourt. 2017b. "Stratégies d'optimisation d'acquisition par drone pour limiter les distorsions lors de la reconstruction 3D par les logiciels Photoscan et MicMac.” Poster presented at Journées CRITEX, Grenoble, May 10-12.

Javernick, L., Brasington, J., and B. Caruso. 2014. "Modelling the topography of shallow braided rivers using Structure-from-Motion photogrammetry." Geomorphology 213: 166-182. doi:10.1016/j.geomorph.2014.01.006.

Kaiser, A., Neugirg, F., Rock, G., Müller, C., Haas, F., Ries, J., and J. Schmidt. 2014. "Small-scale surface reconstruction and volume calculation of soil erosion in complex Moroccan gully morphology using structure from motion." Remote Sensing 6: 7050-7080.

Kromer, R. A., Abellán, A., Hutchinson, D. J., Lato, M., Edwards, T., and M. Jaboyedoff. 2015. “A 4D filtering and calibration technique for small-scale point cloud change detection with a terrestrial laser scanner." Remote Sensing 7: 13029-13052. 
517 Lague, D., Brodu, N. and J. Leroux. 2013. "Accurate 3D comparison of complex topography with terrestrial laser scanner: Application to the Rangitikei canyon (N-Z).” ISPRS Journal of Photogrammetry Remote Sensing 82: 10-26.

Laignel, B. 1997. 'Les altérites à silex de l'ouest du Bassin de Paris: caractérisation lithologique, genèse et utilisation potentielle comme granulats." $\mathrm{PhD}$ diss.,

Lato, M. J., Diederichs, M. S., and D. J. Hutchinson. 2010. "Bias Correction for Viewlimited Lidar Scanning of Rock Outcrops for Structural Characterization.” Rock Mechanics and Rock Engineering 43: 615-628.

Laute, K., Letortu, P., Le Dantec, N. 2017. "Processes and mechanisms governing hard rock cliff erosion in western Brittany, France.” Poster presented at the EGU General Assembly, Vienna, April 23-28.

Letortu, P., Costa, S., Cador, J. M., Coinaud, C., and O. Cantat. 2015a. "Statistical and empirical analyses of the triggers of coastal chalk cliff failure." Earth Surface Processes and Landforms, 40 (10): 1371-1386. doi: 10.1002/esp.3741

Letortu, P., Costa, S., Maquaire, O., Delacourt, C., Augereau, E., Davidson, R., Suanez, S., and J. Nabucet. 2015b. "Retreat rates, modalities and agents responsible for

Lichti, D., and J. Skaloud. 2010. "Registration and calibration.” In Airborne and Terrestrial Laser Scanning, edited by Vosselman G., and H. S. Maas, 83-133. Whittles Publishing: Dunbeath.

544 Lim, M., Rosser, N. J., Petley, D. N., and M. Keen. 2011. "Quantifying the controls and influence of tide and wave impacts on coastal rock cliff erosion." Journal of Coastal Research 27: 46-56. doi:10.2112/JCOASTRES-D-09-00061.1

Medjkane, M., Maquaire, O., Costa, S., Roulland, T., Letortu, P., Fauchard, C., Antoine, R., and R. Davidson. Accepted. "High resolution monitoring of complex coastal 

morphology changes: Cross-efficiency of SfM and TLS based survey (VachesNoires cliffs, Normandy, France)." Landslides.

551

552

553

554

555

556

557

558

559

560

561

562

563

564

565

566

567

568

569

570

571

572

573

574

575

576

577

578

579

580

581

Michoud, C., Carrea, D., Costa, S., Derron, M. H., Jaboyedoff, M., Davidson, R., Delacourt, C., Letortu, P., and O. Maquaire. 2014. "Landslide detection and monitoring capability of boat-based mobile laser scanning along Dieppe coastal cliffs, Normandy." Landslides. doi: 10.1007/s10346-014-0542-5.

Mortimore, R. N., and A. Duperret. 2004. Coastal chalk cliff instability. Engineering Geology Special Publications, London.

Naylor, L. A., Stephenson, W. J., and A. S. Trenhaile. 2010. "Rock coast geomorphology: recent advances and future research directions." Geomorphology 114: 3-11.

Oppikofer, T., Jaboyedoff, M., Blikra, L., Derron, M. H., and R. Metzger. 2009. "Characterization and monitoring of the Åknes rockslide using terrestrial laser scanning." Natural Hazards Earth System Sciences 9: 1003-1009.

Pesci, A., Teza, G., and E. Bonali. 2011. "Terrestrial laser scanner resolution: numerical simulations and experiments on spatial sampling optimization." Remote Sensing 3: $167-184$.

Pirotti, F. 2013. "State of the art of ground and aerial laser scanning technologies for high-resolution topography of the earth surface." EuJRS 46: 66-78.

Pomerol, B., Bailey, H. W., Monciardini, C., and R. N. Mortimore. 1987. "Lithostratigraphy and biostratigraphy of the Lewes and Seaford chalks: a link across the Anglo-Paris basin at the Turonian-Senonian boundary." Cretaceous Research 8: 289-304

Raber, G. T., Jensen, J. R., Hodgson, M. E., Tullis, J. A., Davis, B. A., and J. Berglund. 2007. "Impact of Lidar nominal post-spacing on DEM accuracy and flood zone delineation." Photogrammetry Engineering Remote Sensing 73: 793-804.

Riegl. 2014. Data sheet VZ-400. 4p

Smith, M. W., Carrivick, J. L., Hooke, J., and M. J. Kirkby. 2014. "Reconstructing Flash Flood Magnitudes Using 'Structure-from-Motion': a rapid assessment tool." Journal of Hydrology 519: 1914-1927.

Smith, M. W., Carrivick, J., and D. Quincey. 2016. "Structure from motion photogrammetry in physical geography." Progress in physical geography 40: 247-275 
582

583

584

585

586

587

588

589

590

591

592

593

594

595

596

597

598

599

600

601

602

603

604

Sturzenegger, M., and D. Stead. 2009. "Quantifying discontinuity orientation and persistence on high mountain rock slopes and large landslides using terrestrial remote sensing techniques." Natural Hazards Earth System Sciences 9: 267287.

$\mathrm{Su}$, J., and E. Bork. 2006. "Influence of vegetation, slope, and lidar sampling angle on DEM accuracy.” Photogrammetry Engineering Remote Sensing 72: 1265-1274.

Teza, G., Galgaro, A., Zaltron, N., and R. Genevois. 2007. “Terrestrial laser scanner to detect landslide displacement fields: A new approach.” International Journal Remote Sensing 28: 3425-3446.

Vann Jones, E. C. (née Norman), Rosser, N. J., Brain, M. J., and D. N. Petley. 2015. "Quantifying the environmental controls on erosion of a hard rock cliff." Marine Geology 363: 230-242.

Westoby, M., Brasington, J., Glasser, N., Hambrey, M., and J. Reynolds. 2012. ""Structure-from-Motion" photogrammetry: A low cost, effective tool for geoscience applications." Geomorphology 179: 300-314.

Young, A. P., Olsen, M. J., Driscoll, N., Rick, R. E., Gutierrez, R., Guza, R. T., Johnstone, E., and F. Kuester. 2010. "Comparison of airborne and terrestrial lidar estimates of seacliff erosion in Southern California." Photogrammetric Engineering \& Remote Sensing 76: 421-427.

Young, A. P. 2015. "Recent deep-seated coastal landsliding at San Onofre State Beach, California." Geomorphology 228: 200-212.

\section{Tables}

\begin{tabular}{|c|c|c|c|c|}
\hline Method & $\begin{array}{c}\text { Number of } \\
\text { points }\end{array}$ & $\begin{array}{c}\text { Surface } \\
\left(\mathbf{m}^{\mathbf{2}}\right)\end{array}$ & $\begin{array}{c}\text { Average density } \\
\text { per } \mathbf{~ m}^{\mathbf{2}} \\
\text { on the cliff face }\end{array}$ & $\begin{array}{c}\text { Sampling distance on cliff } \\
\text { face for the raw point cloud }\end{array}$ \\
\hline $\begin{array}{c}\text { Terrestrial } \\
\text { photogrammetry } \\
(\mathbf{T P})\end{array}$ & $124,757,214$ & 13,897 & 8,977 & $\begin{array}{c}\text { Irregular: mean of 1 point } \\
\text { every } 0.0105 \mathrm{~m}\end{array}$ \\
\hline $\begin{array}{c}\text { UAV } \\
\text { photogrammetry } \\
\text { (UAVP) }\end{array}$ & $59,418,289$ & 15,535 & 3,824 & $\begin{array}{c}\text { Regular: mean of 1 point every } \\
0.016 \text { (mean) }\end{array}$ \\
\hline
\end{tabular}




\begin{tabular}{|c|c|c|c|c|}
\hline $\begin{array}{c}\text { Terrestrial laser } \\
\text { scanning (TLS) }\end{array}$ & $2,553,230$ & 14,190 & 178 & $\begin{array}{c}\text { Irregular: mean of 1 point } \\
\text { every 0.06 m (mean) }\end{array}$ \\
\hline
\end{tabular}

605 Table 1. Main characteristics of raw datasets

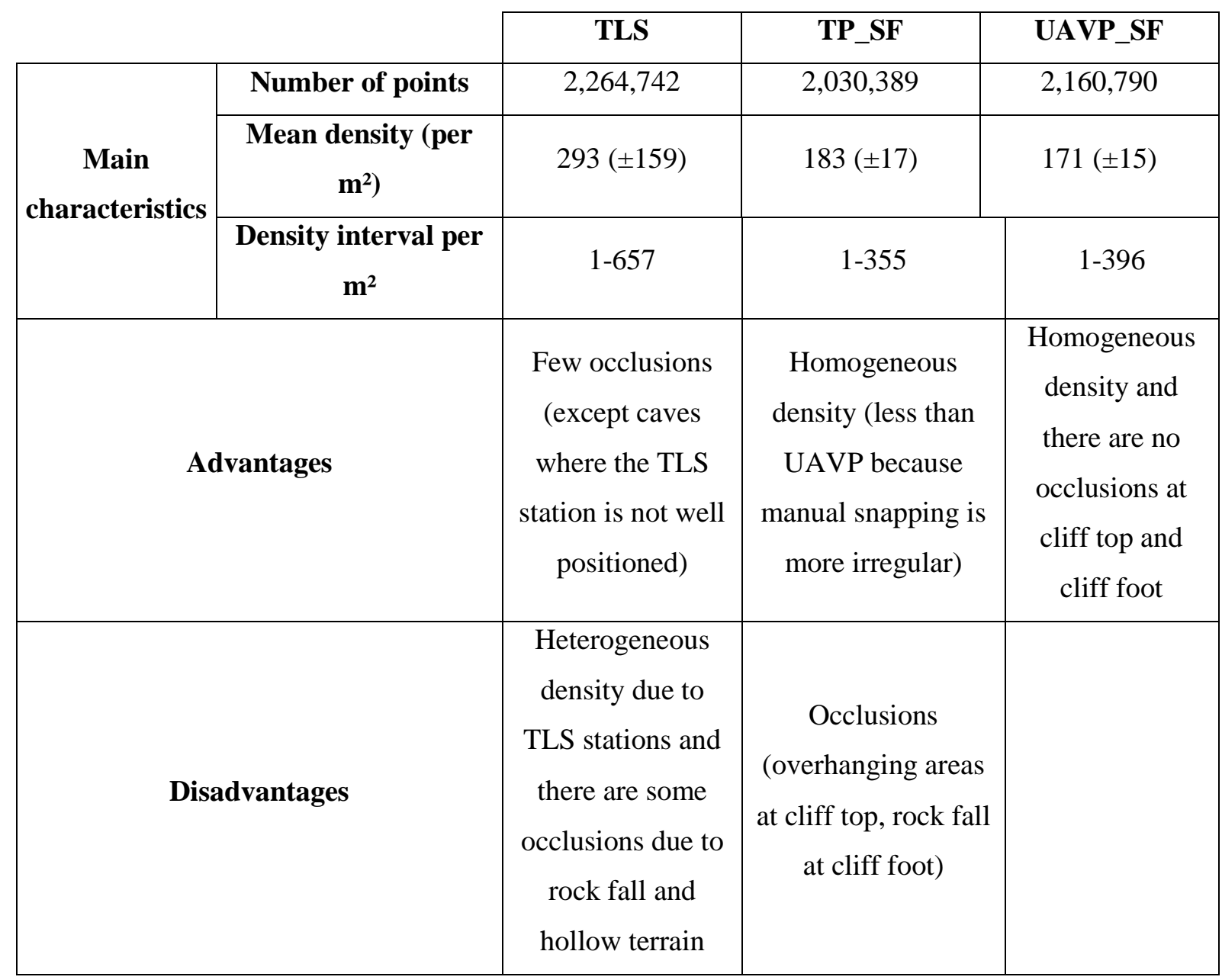

606 Table 2. Characteristics, advantages and disadvantages of the TLS, TP and UAVP point

607 clouds (after subsampling and cleaning)

\begin{tabular}{|c|c|c|c|c|}
\hline \multirow{2}{*}{} & \multicolumn{2}{|c|}{ TP point cloud vs. TLS mesh } & \multicolumn{2}{c|}{ UAVP point cloud vs. TLS mesh } \\
\cline { 2 - 5 } & Mean error & $\begin{array}{c}\text { Standard } \\
\text { deviation }\end{array}$ & Mean error & $\begin{array}{c}\text { Standard } \\
\text { deviation }\end{array}$ \\
\hline Whole cliff face & 0.005 & 0.05 & 0.014 & 0.037 \\
\hline
\end{tabular}

608 Table 3. Mean error and standard deviation values (m) between TP and UAVP whole 609 cliff-face point clouds vs. TLS mesh

\begin{tabular}{|c|c|c|c|}
\hline & TLS & TP & UAVP \\
& (Riegl@ VZ-400 or & (Nikon D800 or & (DS6 + Nikon D800 \\
& similar) & similar) & or similar) \\
\hline
\end{tabular}




\begin{tabular}{|c|c|c|c|}
\hline Precision & high & low & high \\
\hline $\begin{array}{l}\text { Purchase and maintenance } \\
\text { costs }\end{array}$ & $\begin{array}{c}\text { very expensive } \\
\text { (purchase: } 150 \mathrm{k} € \text { ) }\end{array}$ & $\begin{array}{c}\text { cheap (purchase: } \\
1.5 \mathrm{k} €)\end{array}$ & $\begin{array}{c}\text { expensive } \\
\text { (purchase: } 10 \mathrm{k} € \text { ) }\end{array}$ \\
\hline $\begin{array}{c}\text { Weight } \\
\text { (instruments and targets) }\end{array}$ & $\begin{array}{l}\text { very heavy } \\
(33 \mathrm{~kg})\end{array}$ & light $(5 \mathrm{~kg})$ & heavy (9 kg) \\
\hline Battery life & long & very long & short \\
\hline Speed of data acquisition & low & low & very high \\
\hline Sensitivity to occlusion & high & high & very low \\
\hline $\begin{array}{c}\text { Sensitivity to bad weather } \\
\text { (rainfall, wind) }\end{array}$ & high & very low & high \\
\hline Number of man/days & high & low & high \\
\hline $\begin{array}{c}\text { Ability to implement survey } \\
\text { (targets, pilot, station } \\
\text { location) }\end{array}$ & poor & very good & good \\
\hline $\begin{array}{l}\text { Flexibility in the ability to } \\
\text { capture the interest area } \\
\text { (overhanging, caves, etc.) }\end{array}$ & low & low & very high \\
\hline $\begin{array}{c}\text { Level of acquisition skill } \\
\text { needed }\end{array}$ & high & high & very high \\
\hline Acquisition duration & long & long & short \\
\hline Processing duration & long & very long & very long \\
\hline
\end{tabular}

610 Table 4. Summary of strengths (significant strengths in green in the online version, light

611 gray in the print version) and weaknesses (significant weaknesses in red in the online

612 version, dark gray in the print version) of TLS, TP and UAVP methods for Normandy

613 cliff erosion monitoring

614

615 List of figures 


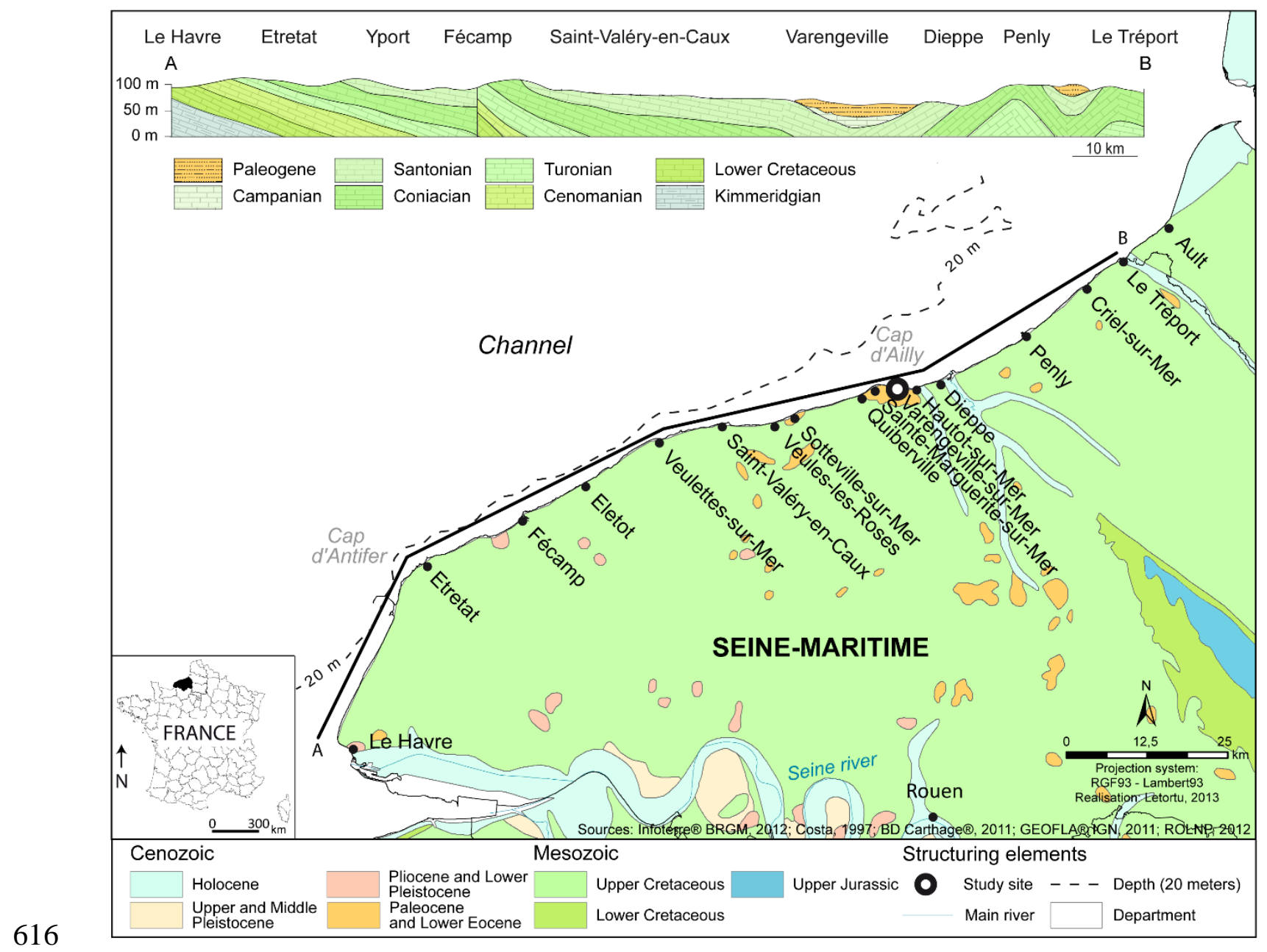

617 Figure 1. Presentation of the study area 

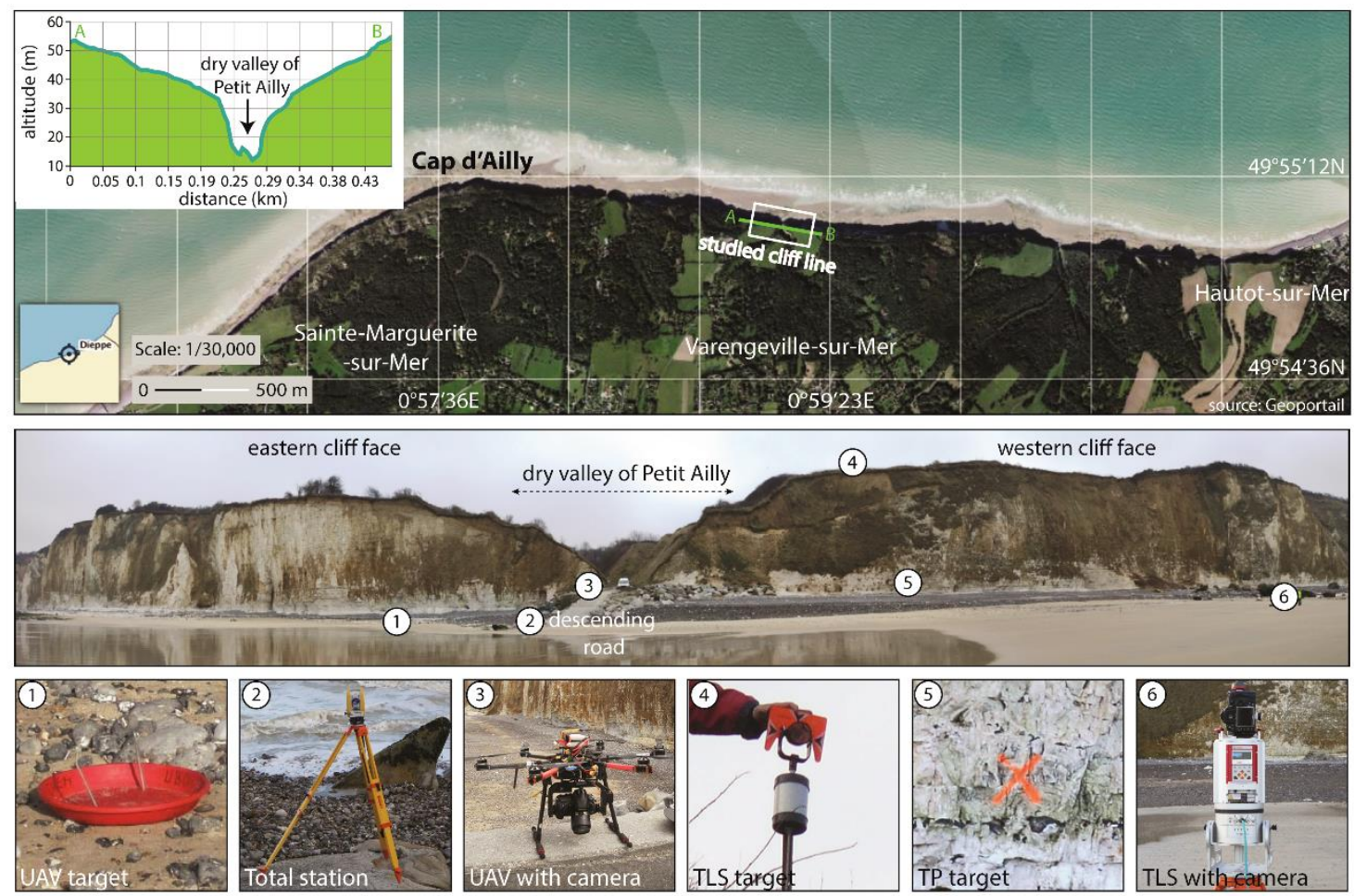

619 Figure 2. Panorama of Petit Ailly cliff face (Varengeville-sur-Mer) and instrumentation 620 used for the survey (28 January 2016)

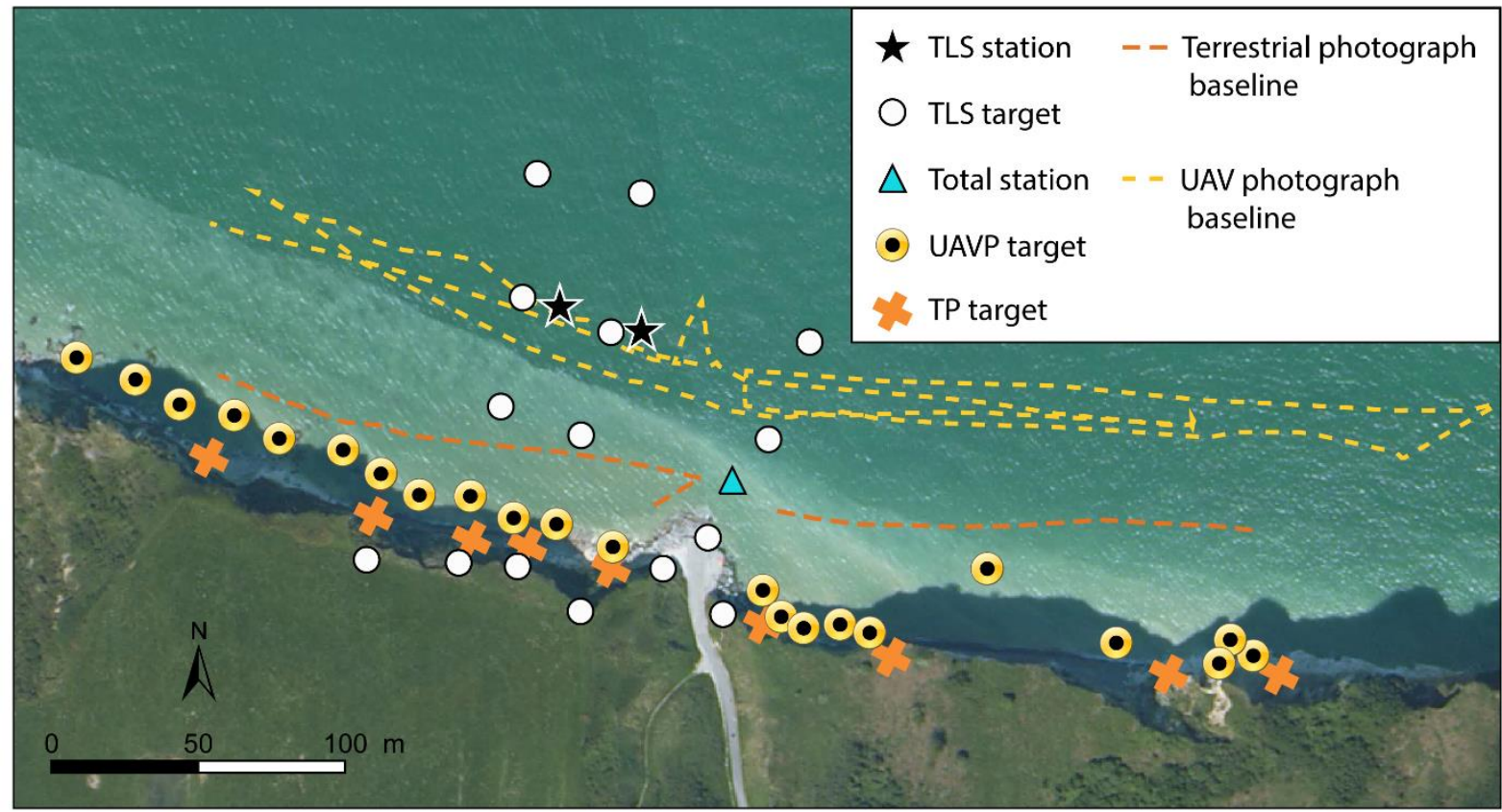

622 Figure 3. Location of the instruments, GCPs and protocol for the survey (28 January

623 2016) (cliff-top view) 


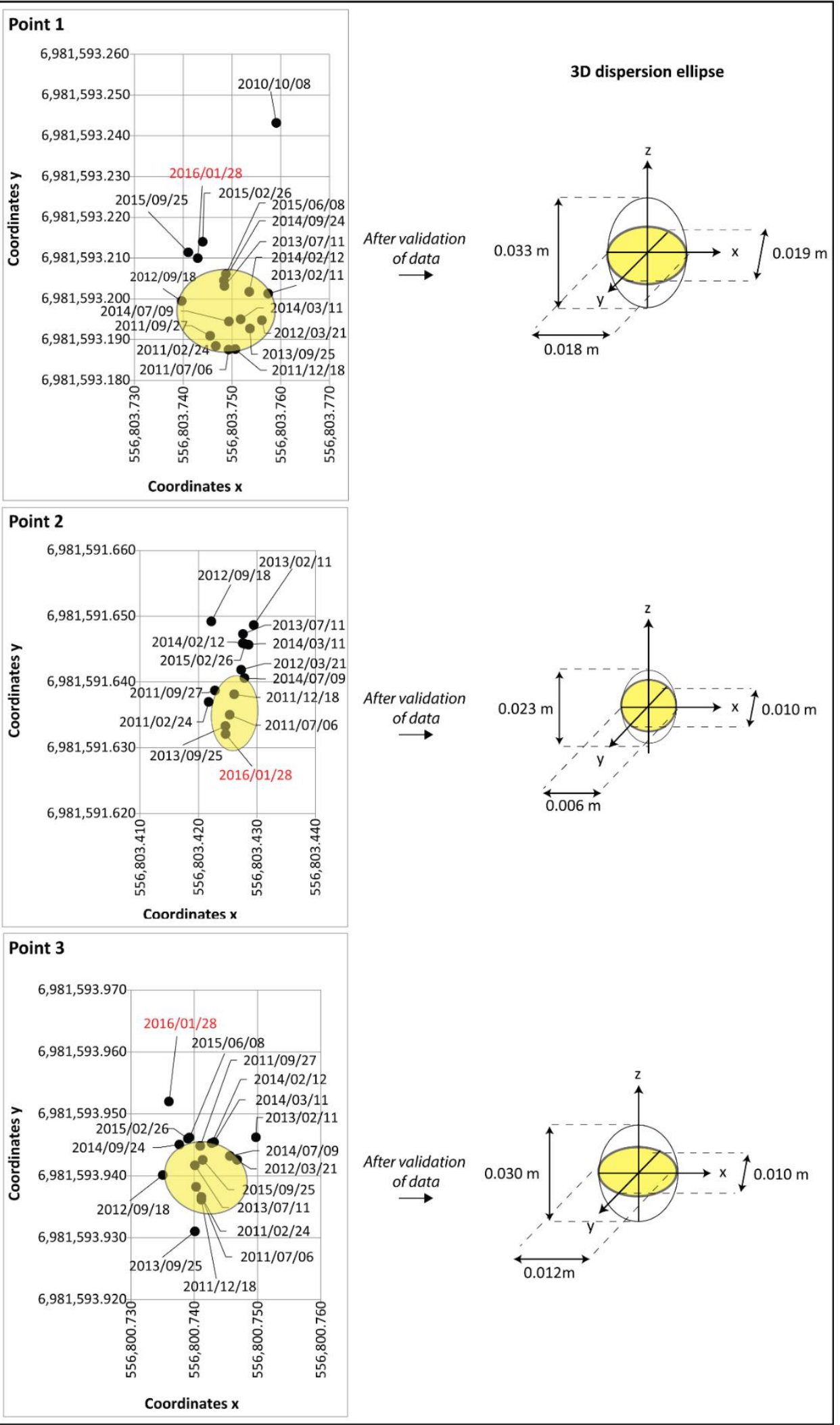

Figure 4. Maximum dispersion ellipses measured by the total station at surveyor nails

627 for the long-term monitoring (the survey used in this paper is depicted in orange in the 628 online edition) 


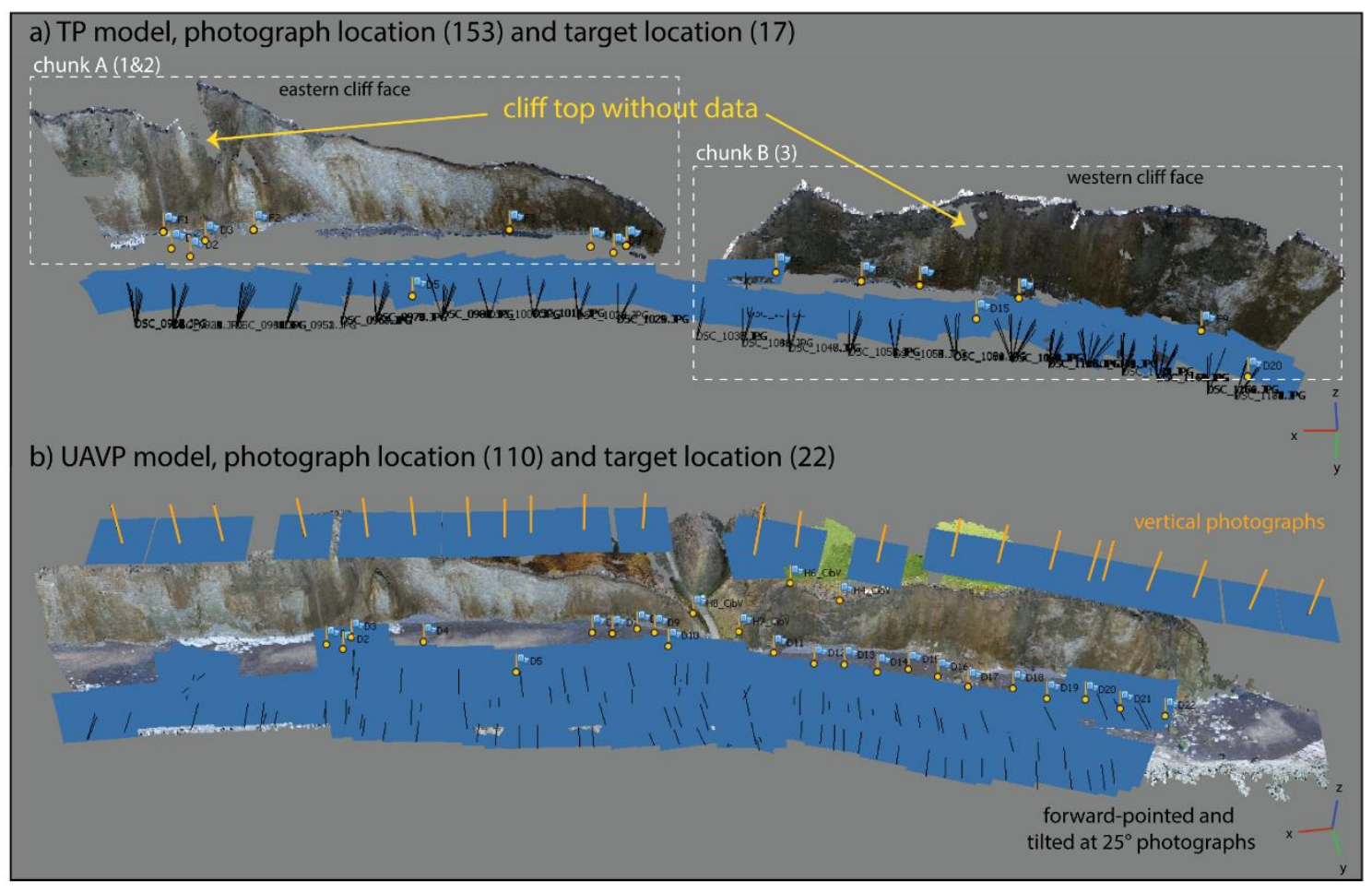

630 Figure 5. Location and overlap of photographs, location of GCPs, and TP and UAVP 631 models 


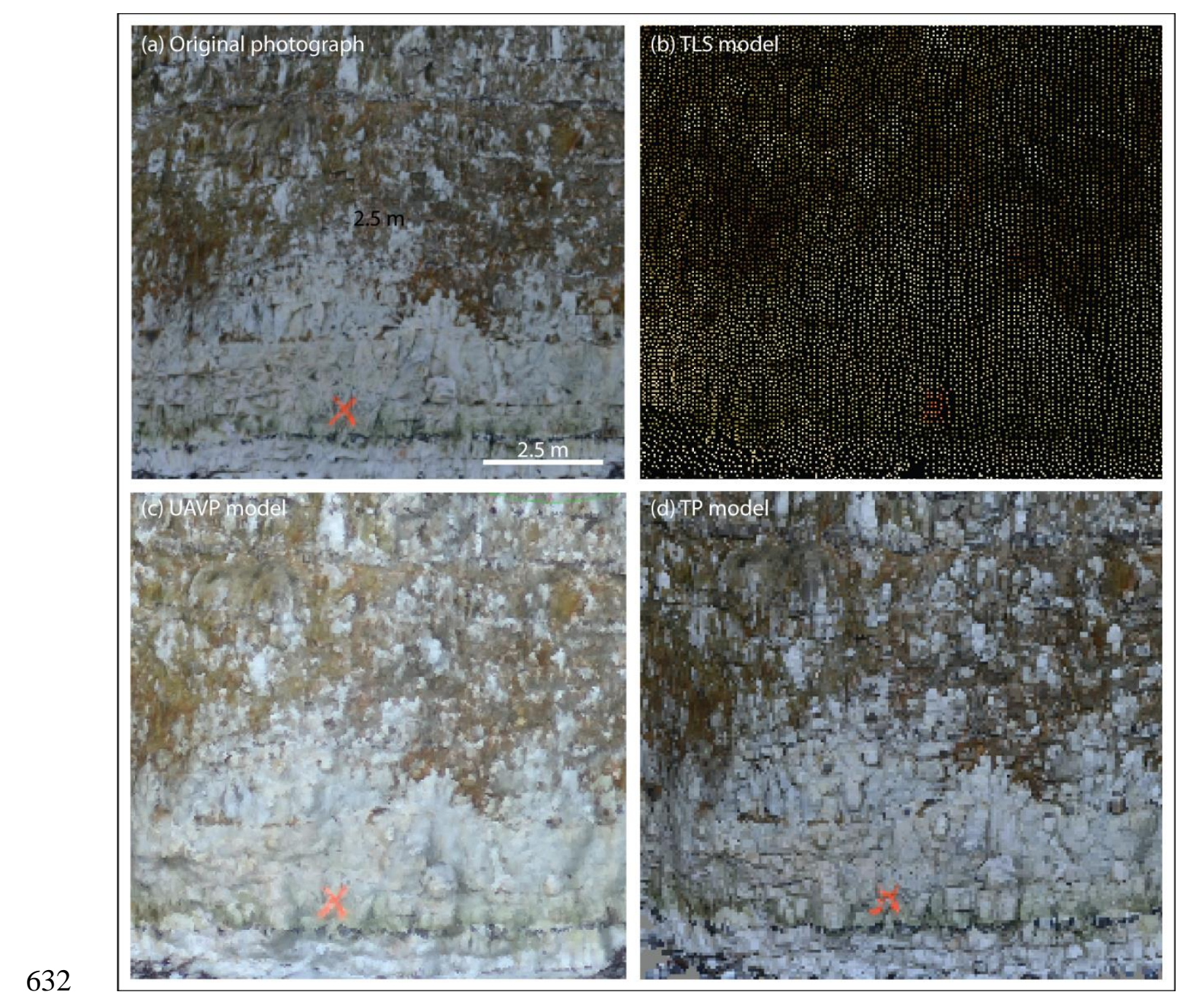

633 Figure 6. Cliff face zoom from (a) original photograph, (b) TLS model, (c) UAVP

634 model and (d) TP model

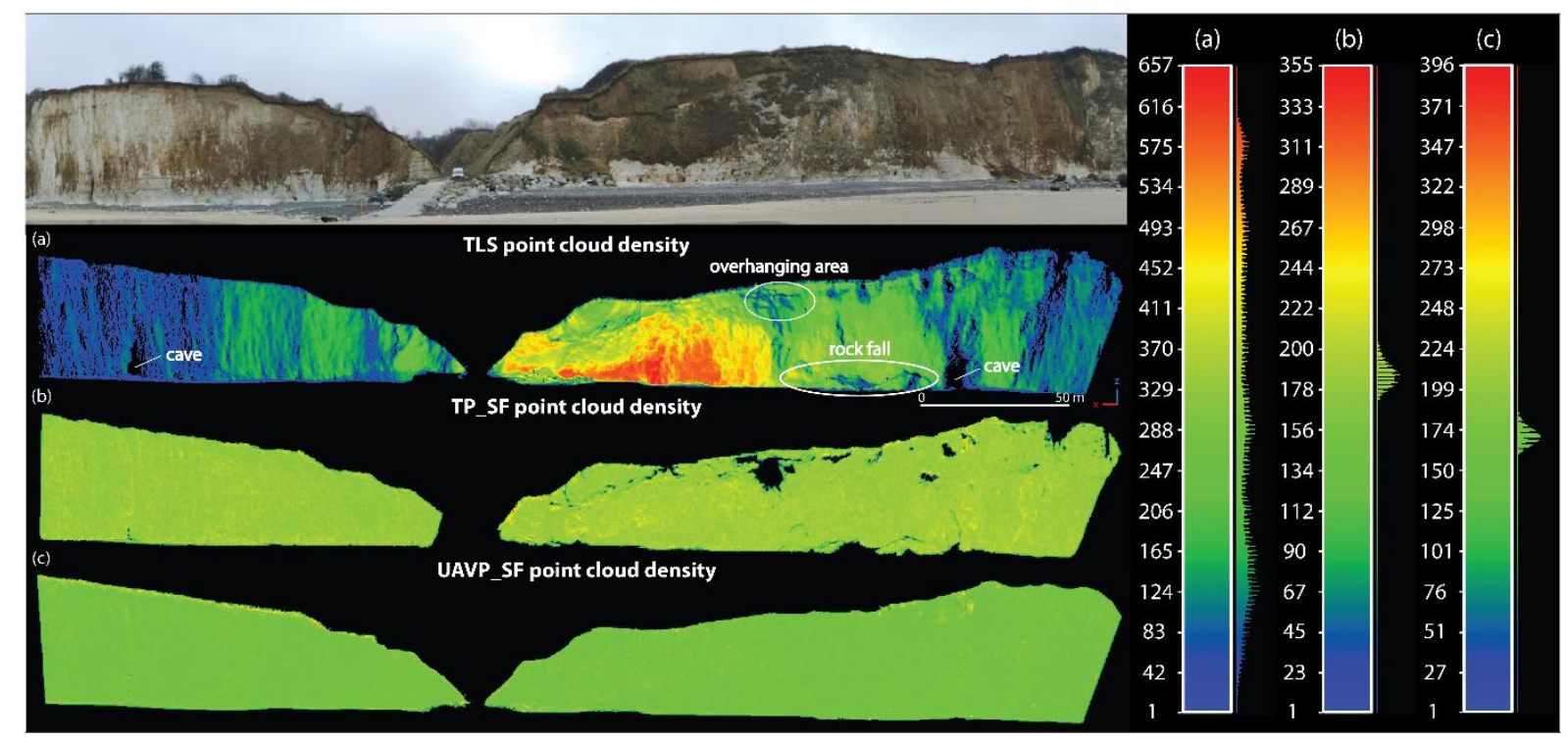


636 Figure 7. Density of point clouds per $\mathrm{m}^{2}$ (TLS, TP, UAVP)

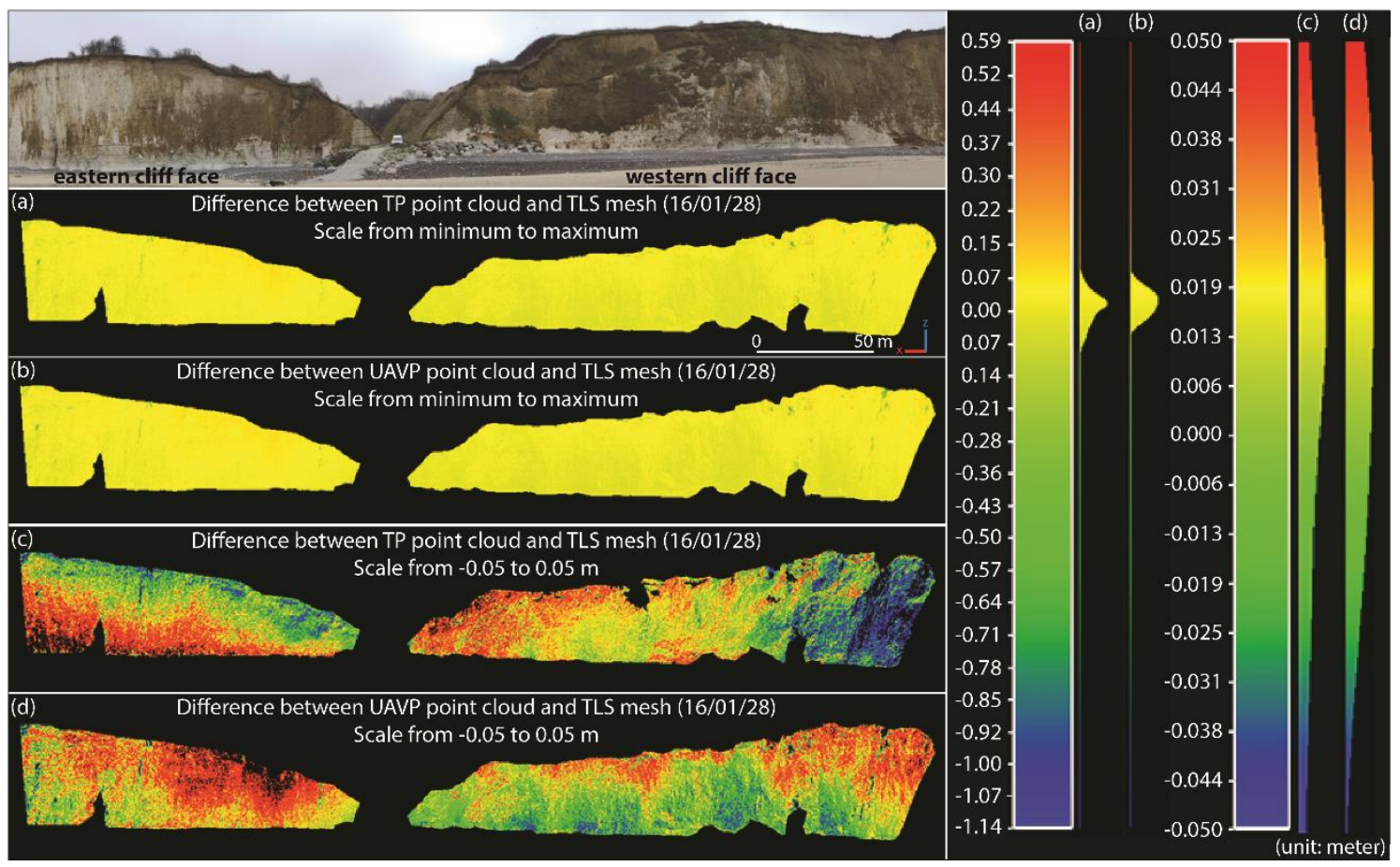

638 Figure 8. Distribution of difference between datasets over the cliff face

639
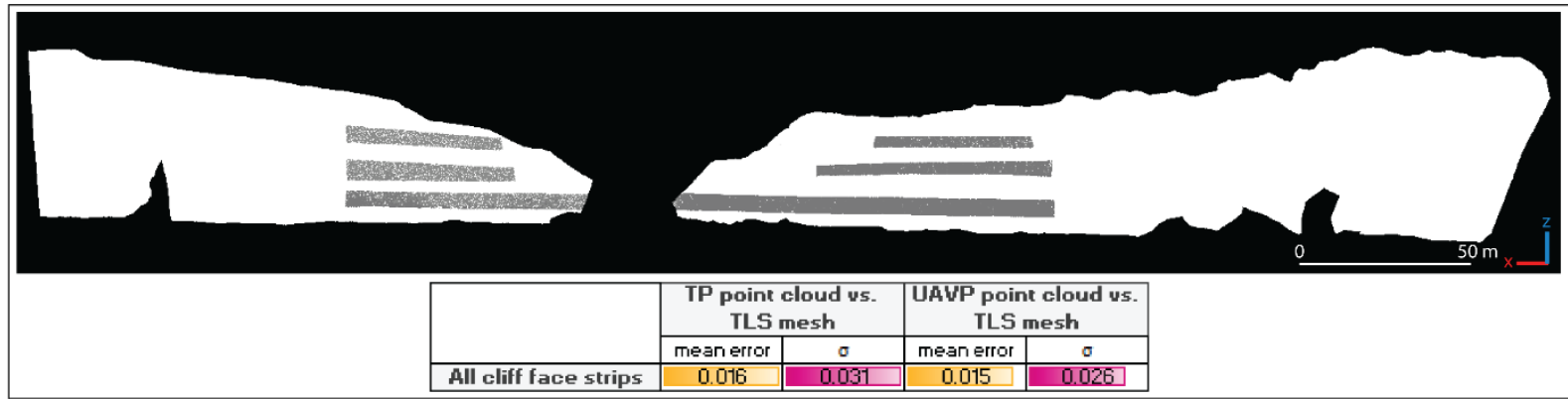

640 Figure 9. Comparison between all cliff-face strip error values and standard deviation 641 
643 Acknowledgements

644 This work is part of the Service National d'Observation DYNALIT, via the research

645 infrastructure ILICO. The authors thank the reviewers for their helpful comments to improve

646 the quality of the manuscript.

647

$648 \quad$ Funding

649 This work was supported by the French "Agence Nationale de la Recherche" through the

650 "Laboratoire d'Excellence" LabexMER [ANR-10-LABX-19-01] program, and co-funded by a

651 grant from the French government through the "Investissements d'Avenir" and the Brittany

652 Region. This work was also supported by the ANR project "RICOCHET: multi-risk assessment

653 on coastal territory in a global change context" funded by the French Research National Agency

654 [ANR-16-CE03-0008]. Finally, this work was supported by the CNES (the French space

655 agency) thanks to TOSCA project EROFALITT. 